\title{
CHEMICAL PROFILE OF TWO JASMINUM SAMBAC L. (AIT) CULTIVARS CULTIVATED IN EGYPT-THEIR MEDIATED SILVER NANOPARTICLES SYNTHESIS AND SELECTIVE CYTOTOXICITY
}

\author{
SEHAM S. EL-HAWARY1, HALA M. EL-HEFNAWY ${ }^{1}$, SAMIR M. OSMAN², EMAN S. MOSTAFA3 , FATMA ALZAHRAA \\ MOKHTAR $^{1 *}$, MOHAMED A. EL-RAEY ${ }^{4}$
}

1, 2Department of Pharmacognosy, Faculty of Pharmacy, Cairo University, Cairo, Egypt, ${ }^{3}$ Department of Pharmacognosy, Faculty of Pharmacy, October University for Modern Sciences and Arts (MSA), $6^{\text {th }}$ October City, Giza, Egypt, ${ }^{4}$ Phytochemistry and Plant Systematic Department, National Research Centre, Dokki, Cairo, Egypt Email: drfatmaalzahraa1950@gmail.com

Received: 17 Apr 2019, Revised and Accepted: 23 Sep 2019

\begin{abstract}
Objective: Evaluation of two Jasminum sambac L. (Ait) cultivars; Arabian Nights (JSA) and Grand Duke of Tuscany (JSG) ethanolic leaves extracts as reducing agents for the green synthesis of silver nanoparticles (AgNPs) and evaluation of their cytotoxicity against MCF-7 breast cancer and 5637 bladder cancer cell lines and chemical profiling of the two cultivars.

Methods: The synthesis of silver nanoparticles (AgNPs) by the two cultivars and characterization of AgNPs by ultraviolet (UV)-visible spectroscopy, Transmission electron microscopy (TEM) and Fourier Transform Infrared Spectroscopy (FTIR). Additionally, the use of The highperformance liquid chromatography coupled with photodiode array-mass-mass-spectroscopy (HPLC-PDA-MS/MS) for chemical profiling of both cultivars and evaluation of total leaves extracts and corresponding nanoparticles towards MCF-7 and 5637 cell lines compared to aneuploidy immortal keratinocyte (Ha Cat) normal cells by neutral cell assay.

Results: The green synthesized AgNPs (of an average size range of 8.83 and $11.24 \mathrm{~nm}$ for JSA and JSG, respectively) exhibited cytotoxicity against MCF-7 and 5637 cell lines. The IC 50 was determined for each total extract JSA $(15.29 \pm 2.16 \mu \mathrm{g} / \mathrm{ml})$ and JSG (20.28 $\pm 1.20 \mu \mathrm{g} / \mathrm{ml})$ and corresponding AgNPs $17.32 \pm 2.22 \mu \mathrm{g} / \mathrm{ml}$ and $6.32 \pm 1.01 \mu \mathrm{g} / \mathrm{ml}$ for JSA and JSG, respectively. The IC 50 of JSA and JSG against 5637 bladder cancer cell line were $13.76 \pm 1.11 \mu \mathrm{g} / \mathrm{ml}$ and $50.69 \pm 3.75 \mu \mathrm{g} / \mathrm{ml}$, while the corresponding AgNPs showed $\mathrm{IC}_{50}$ of $5.54 \pm 0.88 \mu \mathrm{g} / \mathrm{ml}$ and $27.89 \pm 2.84 \mu \mathrm{g} / \mathrm{ml}$, respectively. The HPLC-PDA-MS/MS allowed the identification of 59 compounds; 10 simple phenols, 17 flavonoids; quercetin and kaempferol glycosides, 2 lignans, and 30 secoiridoids; oleuropein, molihauside, and sambacoside.
\end{abstract}

Conclusion: This study proved that JSA is an excellent source for the synthesis of AgNPs with optimum characters and enhanced activities toward MCF-7 and 5637 cell lines in correlation to identified compounds.

Keywords: Jasminum sambac, AgNPs, HPLC-PDA-MS/MS, cytotoxicity, green synthesis

(C) 2019 The Authors. Published by Innovare Academic Sciences Pvt Ltd. This is an open access article under the CC BY license (http://creativecommons.org/licenses/by/4.0/) DOI: http://dx.doi.org/10.22159/ijap.2019v11i6.33646

\section{INTRODUCTION}

Cancer is the second leading death cause 9.6 million death cases worldwide in 2018, most death cases are in low-and-middle-income countries. The most common cancers are breast cancer around 2.09 million cases [1]. Precancerous lesions convert normal cells to malignant tumors due to several factors as exposure to ultraviolet (UV) and infrared (IR) radiation, chemical carcinogens such as tobacco smoke, aflatoxin and arsenic and biological carcinogens due to infectious diseases: viruses, parasites and bacteria and may be due to genetic causes Bladder cancer is the second prominent cancer in males, this type of cancer is resistant for most medical treatments, with the highest incidence in developing countries, most cases of bladder tumor are subjected to tumor recurrence after radical cystectomy [2]. In the early stages, medication therapies are involved in the form of hormonal therapy, targeted therapy [3] or chemotherapy. Several studies have been devoted to the discoveries of new natural therapies that can fight the cancerous cell progression with limited effect on normal cells to achieve the maximum healing properties of breast cancer that can overcome the side effects of previous treatment protocols [4].

Nanoparticle sciences involve recently considerable interest from both academic and industrial fields and spreading of their application practically in medicinal [5-7], electrical [8], agriculture, environment [9] and aquaculture fields due to spontaneous discoveries of their diverse and interesting properties. Development of biologically based and inspired processes for the optimization of nanoparticles characters to target specific diseases or drug delivery pathway is an important branch of nanoscience and nanotechnology. In recent tendency, silver nanoparticles are introduced in medical researches as antimicrobial [10], antifungal, antiviral and cytotoxicity against many cell lines as NIH 3T3 cells and Hela cells [11].

Synthesis of nanoparticles is achieved using chemical, thermal or biological synthesis using bacteria or natural plant extracts $[12,13]$. The biological green pathway involves using of natural plants extracts as reducing agents is more favorable for the development of nanoparticles of optimized characters excluding the effects of chemicals which could alter the nanoparticles characters, toxicity and biological activity [14].

Jasminum sambac L. (Ait), Oleaceae is also known as Arabian Jasmine is native to Middle east and Asia. The two cultivars Jasminum sambac L." Arabian Nights"; (JSA) and Jasminum sambac L."Grand duke of Tuscany"; (JSG) are cultivated in Egypt for thousands of years [15]. Both cultivars are characterized by the high scent aroma of the shiny white composite flowers. They differ from each other by the shape of leaves and the structure of the corolla. They are extensively used in the perfume industry and as a flavoring agent in jasmine tea and aromatherapy [16]. Considerable attention has been gained to Jasminum sambac cultivars and their pharmacological activity[17]. Several studies were performed on its antidiabetic [18], antiinflammatory [19], vasodilator activity [20] and effect on morphine withdrawal symptoms [21]. Additionally, extracts of the flowers were reported to exhibit cytotoxic activity towards brine shrimp Artemia [22], Hep-G2 [23] and Dalton's ascites lymphoma [24].

High-performance liquid chromatography coupled to photodiode array-mass spectroscopy-mass spectroscopy (HPLC-PDA-MS/MS) is 
a type of liquid chromatography-mass spectroscopy used for tentative identification and profiling of the chemical composition and the fragmentation pattern of base peaks of selected plant species [25-27]. This chromatographic technique is used for complete qualitative profiling of secondary metabolites with link to the library for tentative identification.

The current research aims to evaluate the silver nanoparticles (AgNPs) synthesized by the JGA and JSG total ethanolic extracts towards MCF-7 breast cancer cell line and 5637 bladder cancer cell line in comparison to the leaves total extracts. Also, the identification of the chemical composition of the total extracts of leaves was performed using HPLC-PDA-MS/MS technique.

\section{MATERIALS AND METHODS}

\section{Plant material}

The plant leaves were collected in March 2016 from fully mature non flowering stage plants from Keram Farms-Moderayat Al-Tahrir, Behaira, Egypt. Voucher specimens (\# 3.10.16.2), (\#3.10.16.6) for Jasminum sambac L. (Ait) Arabian Nights cultivar and Jasminum sambac L. (Ait) Grand Duke of Tuscany cultivar, respectively are kept at the Department of Pharmacognosy, Faculty of Pharmacy, Cairo University.

\section{Preparation of extracts}

The dry leaves (100) g of each of JSA and JSG were extracted with $99 \%$ ethanol by percolation (4 x 1 L), filtered through Whatmann No.1 filter paper (pore size $0.6 \mathrm{~m}$ ), each filtrate was concentrated under vacuum using rotary evaporator at $45^{\circ} \mathrm{C}$ and lyophilized to yield $24 \%$ and $20 \%$ dry extract, respectively. One hundred mg of each lyophilized extract was used for HPLC-PDAMS/MS analysis, nanoparticles synthesis, characterization, and cytotoxicity study.

\section{Green synthesis of silver nanoparticles (AgNPs)}

AgNPs were synthesized as in the following protocol: $1 \mathrm{Mm}$ aqueous solution of silver nitrate (AgNO3) was prepared and kept in a cool and dark place to use in the synthesis of $1 \mathrm{mmol}$ aqueous solution of silver nitrate (AgNO3) was prepared and used for the synthesis of silver nanoparticles. $10 \mathrm{ml}$ of each ethanolic extract of leaves of JSA and JSG added separately into $90 \mathrm{ml}$ of an aqueous solution of 1 mmol silver nitrate for reduction of Ag+ions and incubated overnight at room temperature in dark place. The resultant yellowish brown solutions were the indication for the formation of silver nanoparticles. The formed solutions were used directly for TEM and UV quantifications [12,13]. Centrifugation at $4000 \mathrm{rpm}$ for $30 \mathrm{~min}$. followed by a series of washing by dist. H20, filtration to obtain pure AgNPs. The pure AgNPs were used for cytotoxicity study.

\section{Characterization of AgNPs}

The UV-Vis spectroscopy of AgNPs were monitored as a function of time in $10 \mathrm{~mm}$ optical path-length-quartz-cuvettes with UV-Vis range 3600 spectrophotometer (Shimadzu, Japan). Samples were diluted 5 times with distilled water before being measured. The morphology of the particles (shape and dimensions) was examined by Transmission electron microscope (TEM). (JEOL-JEM-1011, Japan). Sample for TEM analysis were prepared by placing $3 \mathrm{ml}$ of the sample on the copper grid and kept for drying at room temperature for $15 \mathrm{~min}$. The different functional groups of the prepared nanomaterials in the range of 4000-400 cm_1 were measured by Fourier transform infrared spectroscopy (FTIR) 6100 spectrometer (Jasco, Japan).

\section{Cytotoxicity assay}

Cells of breast cancer cell line (MCF-7) and colon cancer cell line (5637) were obtained from the CLS Cell Lines Service (Eppelheim, Germany). Cells were cultured in RPMI 1640 medium (BioWhittaker, Lonza, Belgium) supplemented with $8 \%$ fetal bovine serum (Sigma
Aldrich, Germany) and antibiotics $(100 \mathrm{U} / \mathrm{ml}$ penicillin/100 $\mu \mathrm{g} / \mathrm{ml}$ streptomycin; Sigma Aldrich, Germany) at $95 \%$ humidity, 5\% CO2 and 37.5 aC. MCF-7 and 5637 cells were sub-cultured twice a week and regularly tested for mycoplasma contamination. Cytotoxicity of test samples investigated cell line using the neutral red uptake (NRU) assay [28]. Statistical analysis of the data was expressed as mean \pm SD for triplicate trials of each measurement.

\section{Therapeutic index}

The therapeutic index is calculated as the ratio between the $\mathrm{IC}_{50}$ of the extract or nanoparticles on the normal keratinocyte cells and the $\mathrm{IC}_{50}$ on the cancer cell line. The drug or extract is considered effective with low cellular toxicity if the therapeutic index (TI) is high [29].

$$
\mathrm{TI}=(\mathrm{IC50} \text { on normal cells }) /(\mathrm{IC} 50 \text { on cancer cells })
$$

\section{HPLC-PDA-MS/MS}

HPLC-PDA-MS/MS using A Thermo Finnigan LC system (Thermo Electron Corporation, Austin, TX, USA). A Zorbax Eclipse XDB-C18; Rapid resolution, $4.6 \times 150 \mathrm{~mm}, 3.5 \mu \mathrm{m}$ column was used (Agilent, Santa Clara, CA, USA). A gradient consisting of water, $0.1 \%$ formic acid and acetonitrile, acetonitrile was increased to $30 \%$ within 60 min with a flow rate $1 \mathrm{ml} / \mathrm{min}$ and a 1:1 split before the ESI source [30]. The sample was injected using autosampler. LCQ-Duo ion trap having a Thermo Quest ESI source was used for MS analysis. Xcalibur software (Xcalibur ${ }^{\mathrm{TM}}$ 2.0.7, Thermo Scientific, Waltham, MA, USA) was used to control the system. MS operating parameters in the negative mode were used as described in [31].

\section{RESULTS AND DISCUSSION}

\section{Nanoparticles characterization}

\section{UV-vis spectroscopy}

UV-vis spectroscopy is a reliable, accurate, simple, selective technique for monitoring the synthesis and stability of AgNPs. AgNPs have unique optical properties, which make them strongly interact with specific wavelengths of light. The conduction band and valence band lie close to each other in which electrons move freely. These free electrons give rise to a surface plasmon resonance (SPR) absorption band due to the collective oscillation of electrons of AgNPs [32]. The absorption of AgNPs depends on the dielectric medium, and chemical surroundings, particles dimensions, and particle size. Observation UV measurements of the formed nanoparticles showed absorbance at $443 \mathrm{~nm}$ for JSA AgNPs and 447 nm for JSG AgNPs.

\section{Transmission electron microscopy (TEM)}

TEM photography fig. (1) Showed biosynthesized AgNPs were predominantly spherical in shape with an average size ranging of 8.83 and $11.24 \mathrm{~nm}$ for JSA AgNPs and JSG AgNPs, respectively.

\section{Fourier transform infrared spectroscopy (FTIR)}

The FTIR spectroscopy analysis was performed to investigate plant metabolites acting as reducing agents for the metal ions to form nanoparticles and supporting their subsequent stability [33, 34]. For JSA and JSG FIG (2A, 2B) The peaks near 3280, 2942 and $1648 \mathrm{~cm}^{-1}$ could be due to the $\mathrm{O}-\mathrm{H}$, aliphatic $\mathrm{C}-\mathrm{H}$ and $\mathrm{C}=\mathrm{O}$ stretching vibration of flavonoids and phenolic groups. The peak $1408 \mathrm{~cm}^{-1}$ corresponds for polyphenol $\mathrm{OH}$ and confirms the presence of an aromatic group, while the absorption peaks at $1012 \mathrm{~cm}^{-1}$ were assigned for $\mathrm{C}-\mathrm{O}-\mathrm{C}$ and secondary $\mathrm{OH}$ group. (In fig. $2 \mathrm{C}, \mathrm{D}$ ), there is a deviation at 3280 and $1648 \mathrm{~cm}^{-1}$ of peak observed for JSA AgNPs and JSG AgNPs fig. (2 C, D). It suggests that the $\mathrm{O}-\mathrm{H}$ and $\mathrm{C}=\mathrm{O}$ groups were adsorbed on the surface of AgNPs have a deterministic role in the reduction of silver nitrate for AgNPs formation. These functional groups are attributed to flavonoids and secoiridoids the main components of the extracts. 

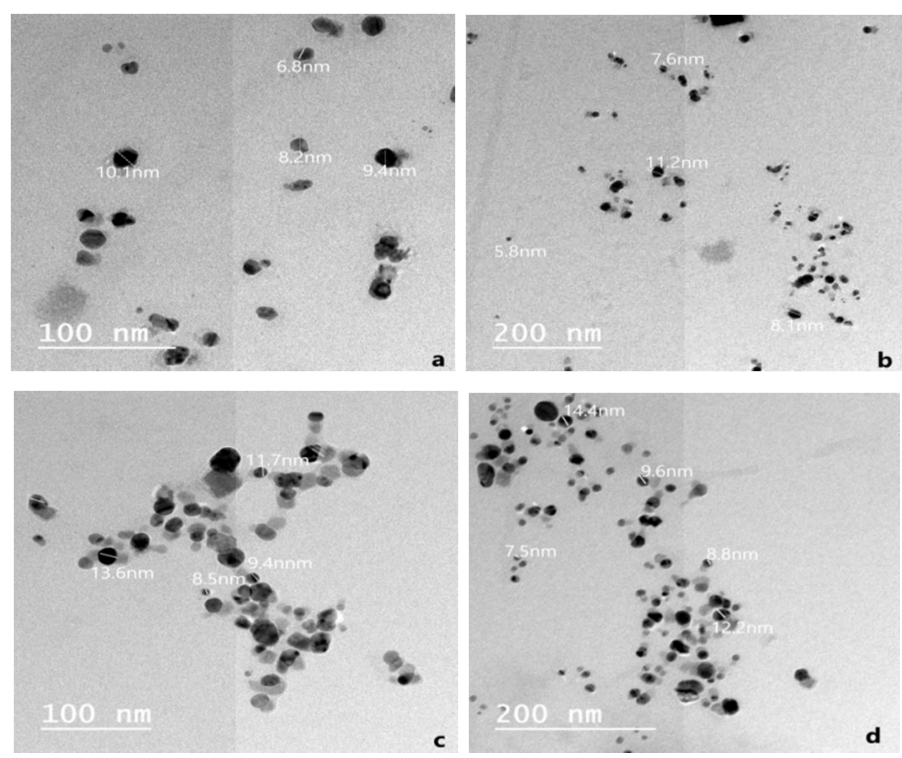

Fig. 1: TEM of silver nanoparticles biosynthesized using JSA; a (100 nm), b (200 nm) and JSG; c (100 nm), d (200 nm)
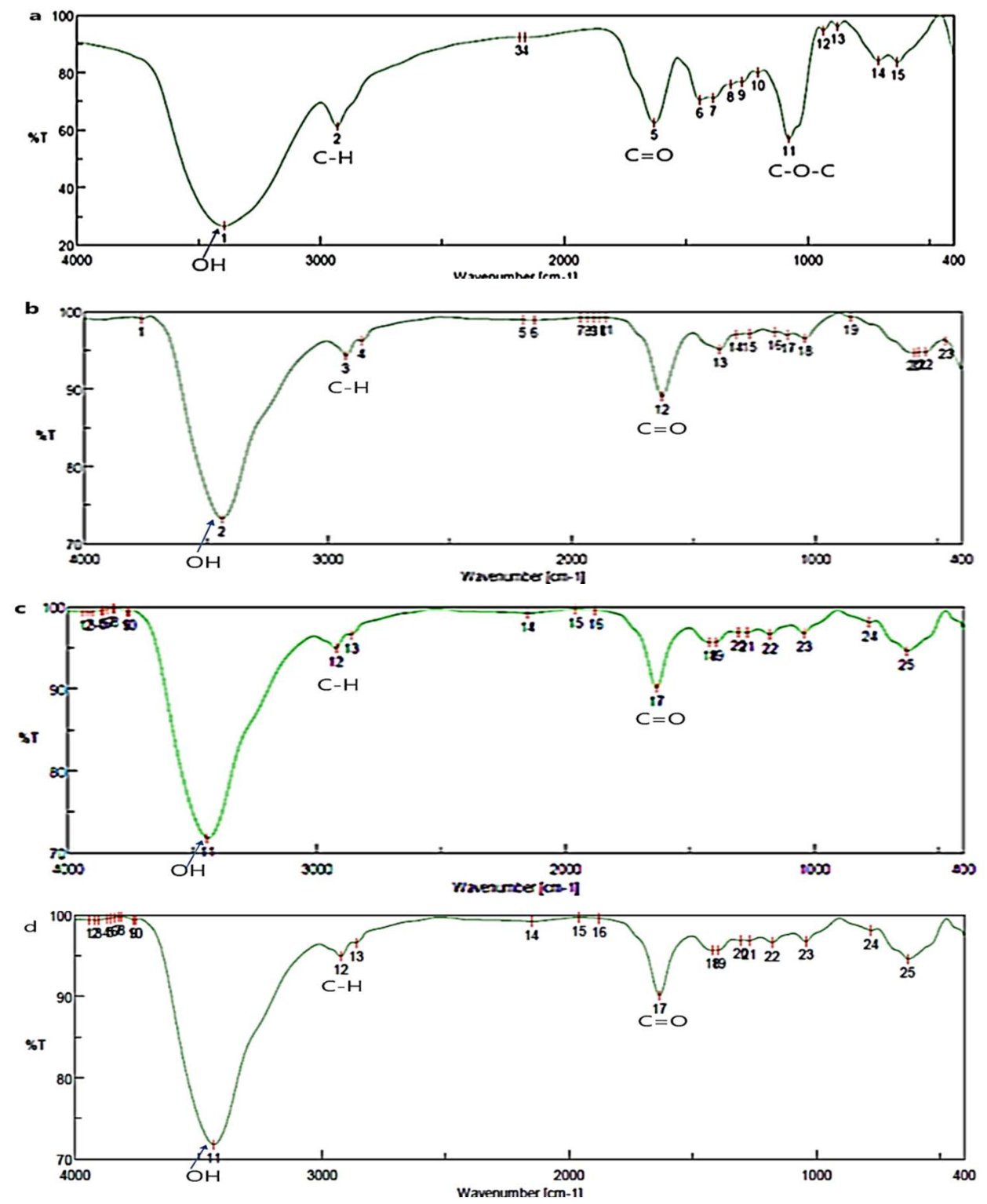

Fig. 2: FTIR spectra of a; total ethanolic leaves extract of JSA, b; JSA AgNPs, c; total ethanolic leaves extract of JSG, d; JSG AgNPs 


\section{Cytotoxicity results}

Both ethanolic extracts of cultivars of Jasminum sambac possessed cytotoxic activities against MCF-7 cell lines JSA $\left(\mathrm{IC}_{50}=15.29 \pm 2.16\right.$ $\mu \mathrm{g} / \mathrm{ml}$ ), while JSG showed lower ( $\mathrm{IC}_{50}=20.28 \pm 1.20 \mu \mathrm{g} / \mathrm{ml}$ ) indicating both Jasminum sambac cultivars show cytotoxicity with a higher cytotoxic effect of the total ethanolic extract of JSA than JSG. The corresponding synthesized AgNPs showed higher cytotoxicity toward the MCF-7 breast cancer cell line with $\left(\mathrm{IC}_{50}=6.32 \pm 1.01\right.$ $\mu \mathrm{g} / \mathrm{ml}$ ) for JSA AgNPs and ( $\mathrm{IC}_{50}=17.32 \pm 2.22 \mu \mathrm{g} / \mathrm{ml}$ ) for JSG AgNPs. JSA AgNPs were more effective than the standard drug etoposide.
$\mathrm{IC}_{50}$ are arranged in the following order JSA AgNPs>etoposide> JSA>JSG AgNPs>JSG. Table (1), fig. 3.

The cytotoxicity of ethanolic extract of JSA against 5637 bladder cancer cell line $\left(\mathrm{IC}_{50}=13.76 \pm 1.11 \mu \mathrm{g} / \mathrm{ml}\right)$ while ethanolic extract of JSG $\left(\right.$ IC $_{50}=50.69 \pm 3.75 \mu \mathrm{g} / \mathrm{ml}$ ), meanwhile corresponding AgNPs exhibited better cytotoxicity on 5637 cell line with $\left(\mathrm{IC}_{50}=5.54 \pm 0.88\right.$ $\mu \mathrm{g} / \mathrm{ml}$ ) and ( $\mathrm{IC}_{50} 27.89 \pm 2.84 \mu \mathrm{g} / \mathrm{ml}$ ) for JSA AgNPs and JSG AgNPs, respectively. Both extracts and their corresponding AgNPs have very low toxicity toward normal cell line $(\mathrm{Ha} \mathrm{CaT})>300 \mu \mathrm{g} / \mathrm{ml}$ as illustrated in table (1), fig. $(2,3)$.

Table 1: IC $5_{00}$ of JSA and JSG ethanolic extracts and their corresponding AgNPs on cell lines; MCF-7 breast cancer and 5637 bladder cancer and normal keratinocyte (Ha CaT) using selective standard drugs etoposide for (MCF-7) and Vincristine for (5673) cell lines

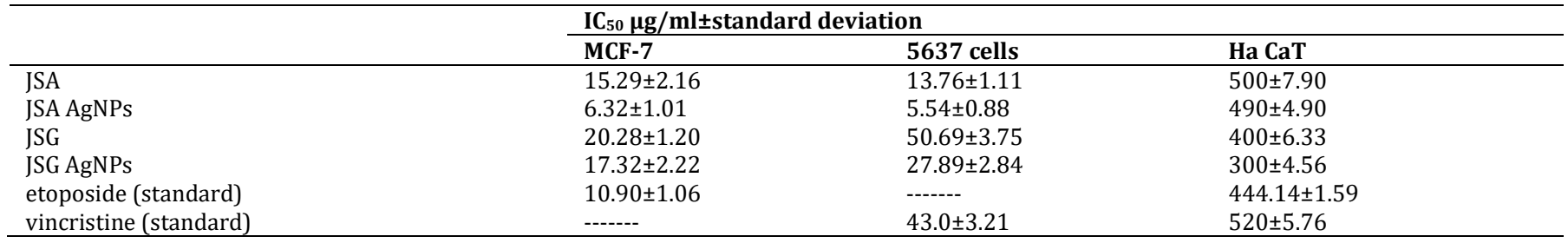

Values are expressed as mean $\pm \mathrm{SD}(\mathrm{N}=3)$

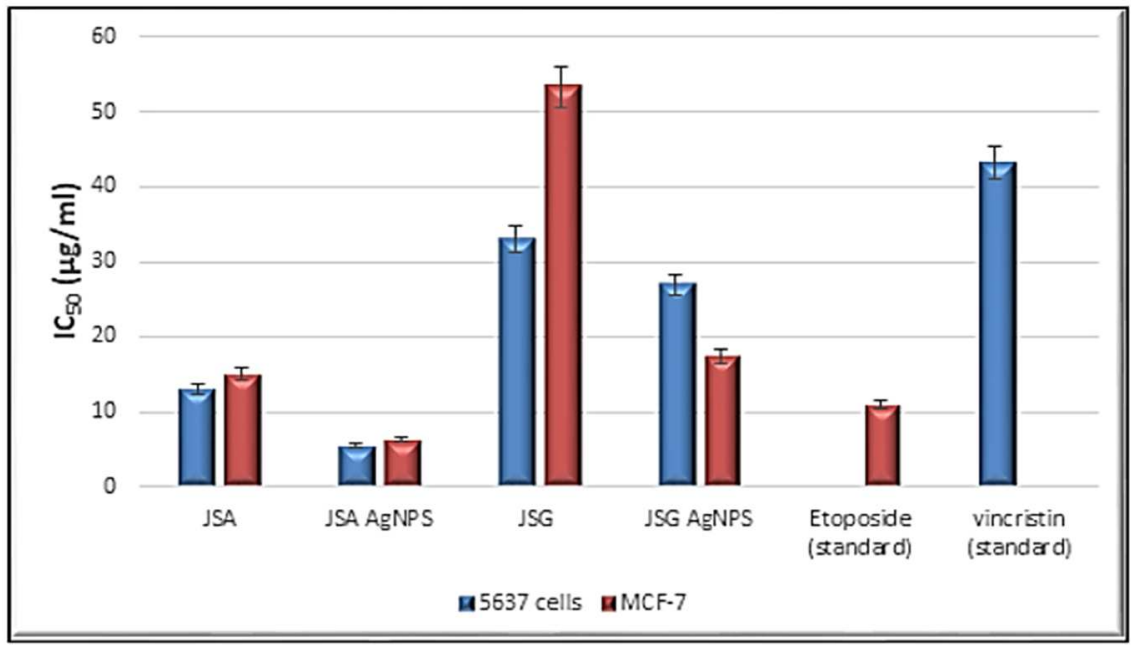

Fig. 3: IC 50 of ethanolic extracts of leaves of JSA and JSG ethanolic extracts and their corresponding synthesized AgNPs on MCF-7 breast cancer and 5637 bladder cancer cell lines (Values are expressed as mean \pm SD)

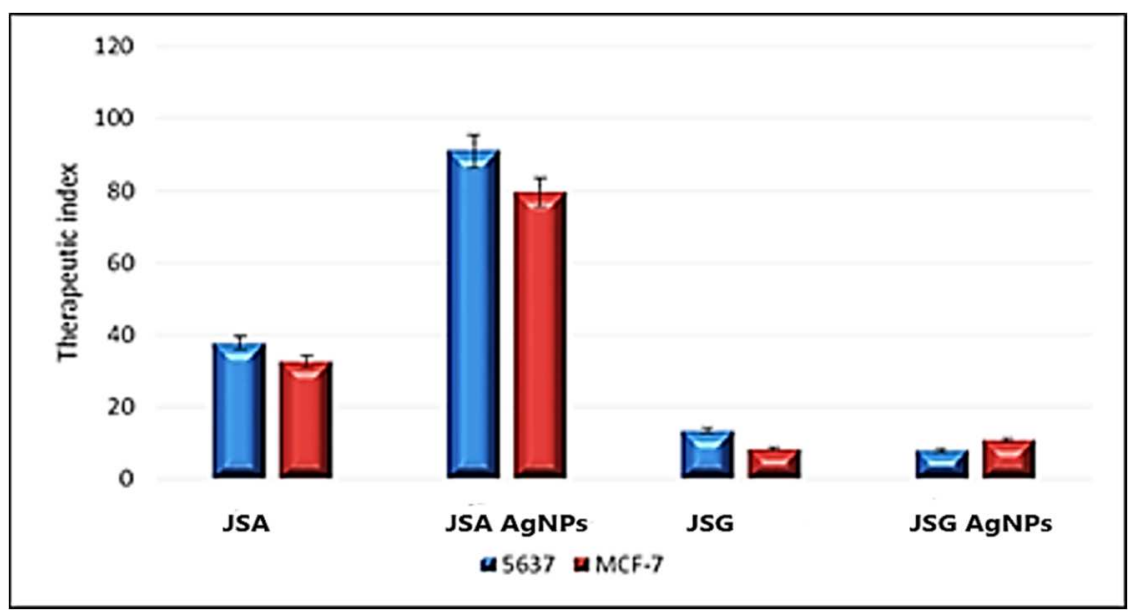

Fig. 4: Therapeutic index of ethanolic extracts of leaves of JSA and JSG and their corresponding synthesized AgNPs on MCF-7 breast cancer and 5637 bladder cancer cell lines 
By calculating the therapeutic indices of JSA and JSG and their corresponding AgNPs, all the tested extracts and AgNPS have a good TI but a very high TI of JSA AgNPs toward both cell lines: MCF-7 breast cancer cell line (93.5) and the 5637 bladdetr cell line (81.3). Indicating the effectiveness of JSA AgNPs toward the two cell lines with very low cellular toxicity.

\section{HPLC-PDA-MS/MS}

Phytoconstituents of the two Jasminum sambac cultivars were identified via HPLC-PDA-MS/MS, a total of 59 compounds were identified as listed in table (2) and fig. (4), assignments were done by comparing retention times data and UV-vis spectral data for the screening and qualitative determination of phenolic acids, secoiridoids glycosides and flavonoids in plants has been illustrated with the ethanolic leaves extracts of Jasminum sambac (Ait.) cultivars. In this paper, it has been shown that parent ion scan and base peaks are powerful tools to identify the presence of certain compounds often occurring in genus Jasminum, interpretation of HPLC-PDA-MS/MS of JSA and JSG showed some variations among these 2 cultivars, JSA result in tentative identification of 42 compounds the main class is the secoiridoid glycosides 23 compounds and 2 lignans in addition to simple phenols and flavonoids. While in JSG cultivar a total of 26 compounds were tentatively identified composed of 9 secoiridoids, 7 phenolic acids derivatives, and 9 flavonoid glycosides and one lignan. Table (2), fig. 4

\section{Identification of simple phenols and phenolic acids}

Simple phenols i.e. free hydroxytyrosol (2) and hydroxytyrosol hexoside (1) with molecular ion peaks at [M-H]-of m/z 315, 153 were identified in JSA, while not identified in JSG. Phenolic acids and derivatives; caftaric acid, caftaric acid rhamnoside, ethyl cinnamate, syringic acid, and salvianolic acid were determined in JSG, and coumaroyl hexoside has been detected in JSA only. Protocatechualdehyde and sinapoyl hexoside were detected in both cultivars.
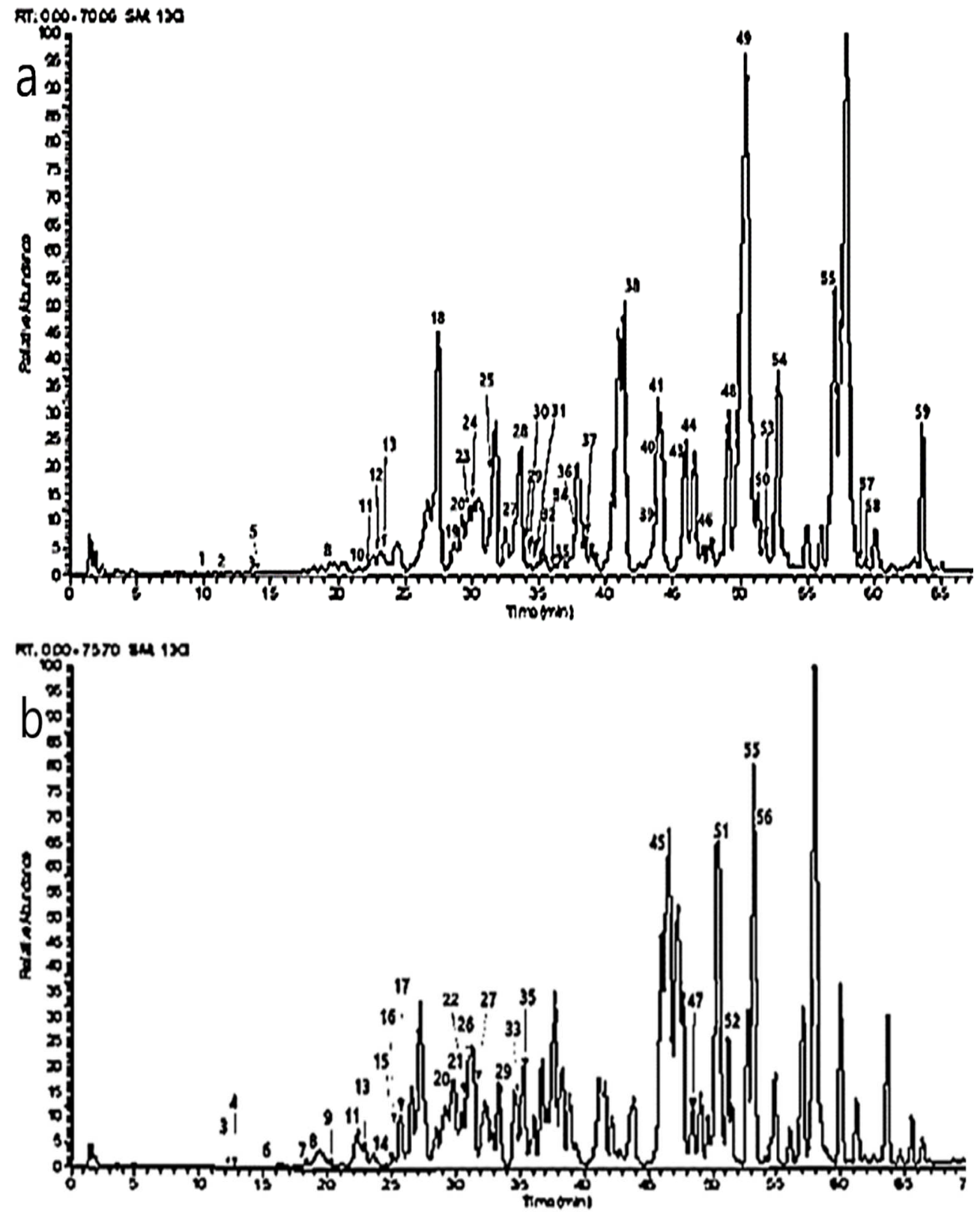

Fig. 4: Total ion chromatogram of ethanolic extracts of leaves of $a$; JSA and $b$; JSG 
Table 2: Tentative identification of the chemical profile of ethanolic extracts of leaves of JSA and JSG using HPLC-PDA-MS/MS in the negative ion mode

\begin{tabular}{|c|c|c|c|c|c|c|c|c|}
\hline No. & tr.(min) & JSA & JSG & {$[\mathrm{M}-\mathrm{H}]^{-}$} & MS/MS & UV (nm) & Identified compound & Ref. \\
\hline 1 & 9.65 & + & - & 315 & 153,123 & 278 & hydroxy tyrosol hexoside & [35] \\
\hline 2 & 11.27 & - & + & 153 & 123 & 277 & hydroxy tyrosol & [35] \\
\hline 3 & 12.2 & + & + & 137 & 109 & 277 & Protocatechualdehyde & [36] \\
\hline 4 & 12.39 & - & + & 447 & 311 & 276 & caftaric acid rhamnoside & \\
\hline 5 & 14.05 & + & - & 325 & 163 & 260,282 & coumaroyl hexoside & {$[36,37]$} \\
\hline 6 & 15.4 & - & + & 175 & 147 & 268 & ethyl cinnamate & [38] \\
\hline 7 & 18.39 & - & + & 567 & 405 & 229,278 & oleoside 11 methy ester hexoside & [39] \\
\hline 8 & 19.02 & + & + & 565 & 403 & 229,278 & 10-hydroxy oleoside hexoside & {$[40]$} \\
\hline 9 & 20.59 & - & + & 311 & 267,249 & 276 & caftaric acid & {$[41,42]$} \\
\hline 10 & 21.44 & + & - & 755 & 593,285 & 342 & kaempferol rutinoside hexoside & [43] \\
\hline 11 & 22.42 & + & + & 537 & 375 & n. d. & cycloolivil hexoside & [44] \\
\hline 12 & 22.73 & + & - & 403 & 223 & 227,277 & oleoside 11 methyl ester & [45] \\
\hline 13 & 22.94 & + & + & 385 & 223 & 269,282 & sinapoyl hexoside & [46] \\
\hline 14 & 24.92 & - & + & 197 & 171,153 & 266,281 & syringic acid & {$[47,48]$} \\
\hline 15 & 25.02 & - & + & 491 & 293,191 & 265,290 & salvianolic acid & [49] \\
\hline 16 & 25.32 & - & + & 755 & 593,447 & n. d. & quercetin hexosyl dirhamnoside & [50] \\
\hline 17 & 25.63 & - & + & 521 & 389 & 224,280 & oleoside pentoside & [51] \\
\hline 18 & 27.48 & + & - & 625 & 463,301 & 346 & quercetin dihexoside & [52] \\
\hline 19 & 28.44 & + & - & 393 & 311,179 & 233 & jasmolactone B & [53] \\
\hline 20 & 28.59 & + & + & 609 & 463,301 & 352 & quercetin rutinoside & {$[54,55]$} \\
\hline 21 & 30.23 & - & & 739 & 285 & 344 & kaempferol hexoside dirhamnoside & [43] \\
\hline 22 & 30.56 & - & + & 771 & 609,285 & 345 & kaempferol trihexoside & [56] \\
\hline 23 & 30.81 & + & - & 609 & 447,285 & 344 & kaempferol dihexoside & [56] \\
\hline 24 & 30.86 & + & - & 589 & 353,209 & n. d. & hydroxy jasmesosidic acid methyl ester & [39] \\
\hline 25 & 31.27 & + & - & 913 & 895,209 & n. d. & jasmosidic acid & [57] \\
\hline 26 & 31.44 & - & + & 609 & 447,301 & 353 & quercetin hexosyl rhamnoside & [38] \\
\hline 27 & 31.96 & - & + & 593 & 447,285 & 342 & kaempferol rutinoside & [50] \\
\hline 28 & 32.76 & + & - & 463 & 301,179 & 350 & quercetin hexoside & [38] \\
\hline 29 & 33.97 & + & + & 623 & 461,315 & 336 & isorhamnetin hexosyl rhamnoside & [58] \\
\hline 30 & 34.15 & + & - & 555 & 389,345 & 231,280 & Jaspolinaloside & [59] \\
\hline 31 & 34.25 & + & - & 579 & 433,301 & n. d. & quercetin rhamnosyl pentoside & [38] \\
\hline 32 & 35.37 & + & - & 579 & 417,285 & 342 & kaempferol pentosyl hexoside & [56] \\
\hline 33 & 35.69 & - & - & 433 & 301 & 348 & quercetin pentoside & [38] \\
\hline 34 & 36.22 & + & - & 499 & 315 & n. d. & jasmolactone $\mathrm{C}$ & {$[60]$} \\
\hline 35 & 36.65 & + & + & 447 & 285 & 344 & kaempferol hexoside & [61] \\
\hline 36 & 37.01 & + & - & 701 & 539 & 232,277 & oleuropein hexoside & [62] \\
\hline 37 & 38.49 & + & - & 685 & 523 & 230,277 & ligstroside hexoside & [63] \\
\hline 38 & 42.36 & + & - & 403 & 241,223 & 226,280 & elenoic acid hexoside & [64] \\
\hline 39 & 43.32 & + & - & 677 & 515 & 231,277 & Multifloroside & [65] \\
\hline 40 & 43.88 & + & - & 839 & 667 & 231,282 & caffeoyl multifloroside & [65] \\
\hline 41 & 44.15 & + & - & 539 & 377 & 233,277 & Oleuropein & [66] \\
\hline 42 & 44.78 & - & + & 593 & 447,301 & 282,339 & caffeoyl kaempferol rhamnosyl & [67] \\
\hline 43 & 45.87 & + & - & 975 & 813 & 233 & deacylsambacoside $\mathrm{A}$ isomer & [68] \\
\hline 44 & 46.02 & + & - & 1071 & 839 & 234 & Polyanoside & [69] \\
\hline 45 & 46.66 & - & + & 975 & 813,589 & 234 & molihuaside A & [68] \\
\hline
\end{tabular}

Table 2: Tentative identification of the chemical profile of ethanolic extracts of leaves of JSA and JSG using HPLC-PDA-MS/MS in the negative ion mode

\begin{tabular}{llllllll}
\hline No & tr (min) & JSA & JSG & [M-H] & MS/MS & UV(nm) & Identified compound \\
\hline 46 & 47.13 & + & - & 945 & 783,421 & 229 & jasnudifloside H \\
47 & 48.69 & - & + & 1347 & 589 & 231 & dihydrojasuroside A \\
48 & 49.51 & + & - & 1347 & 1183,961 & 222,276 & dihydro jasnudifloside B \\
49 & 50.37 & + & - & 975 & 813,589 & 226 & deacylsambacoside A isomer \\
50 & 51.45 & + & - & 523 & 377 & 231,277 & Ligstroside \\
51 & 51.58 & - & + & 921 & 759,389 & 235 & sambacolignoside \\
52 & 51.69 & - & + & 965 & 921,759 & 233 & carboxy sambacolignoside \\
53 & 52.12 & + & - & 375 & 195,179 & n. d. & Cycloolivil \\
54 & 53.31 & + & - & 819 & 539 & 226,278 & jaspolyanthoside \\
55 & 53.42 & + & + & 1361 & 961,589 & 229 & sambacoside A \\
56 & 53.75 & - & + & 945 & 713,559 & 233 & [63] \\
57 & 59.19 & + & - & 285 & 267,251 & 341 & [72] \\
58 & 59.62 & + & - & 909 & 523 & 229 & Kasnudifloside H \\
59 & 63.15 & + & - & 943 & 727,595 & 227 & [73] \\
\hline
\end{tabular}

No: compound number $\operatorname{tr}(\mathrm{min})$ : retention time in minutes Ref: reference, ${ }^{*}$ compounds are numbered according to elution from the column 


\section{Identification of secoiridoids}

Secoiridoids are the characteristic key elements in the Oleaceae family[77]. Secoiridoid glycosides are secoiridoids attached to phenolic compound: ligstroside and oleuropein or secoiridoids attached to tetraol structure as sambacoside A or secoiridoids attached to lignans; sambacolignoside. In this study 30 secoiridoids were identified via HPLC-PDA-MS/MS (peaks 7, 8, 12, 17, 19, 24, 25 , $30,34,36-41,43-51,53-56,58$ and 59). Oleuropein derivatives are the major secoiridoid class in this plant family were assigned in peaks $39,40,41$ and 44 with a corresponding molecular ion [M-H]of $\mathrm{m} / \mathrm{z} 677,839,539$ and 1071, respectively. A major abundance of tetraol dimeric and trimeric secoiridoid hexosides was detected dimeric secoiridoids peaks $25,43,45,49,54$ and 58 with a corresponding molecular ion [M-H] of m/z 913, 975, 975, 975, 819 and 909 respectively, compounds with the same mass distinguished from each other by the fragmentation pattern, tetraol trimeric secoiridoid glycosides was represented in peaks 47,48 and 55 and with a corresponding molecular ion [M-H] of $\mathrm{m} / \mathrm{z} 1347,1347$, and 1361 respectively. Peak 55 (sambacoside A) is the characteristic compound in both Jasminum sambac cultivars, secoiridoids lactones were determined and represented by the peaks 19, 34 with a corresponding molecular ion [M-H]-of $\mathrm{m} / \mathrm{z} 393$ and 499 respectively. Secoiridoid gconjugated to lignin was assigned in the peak 51 (sambacolignoside) with molecular ion $[\mathrm{M}-\mathrm{H}]-$ of $\mathrm{m} / \mathrm{z} 921$. Most other secoiridoids identified are classified as oleoside derivatives with different substitutions at 7,11 and 10 positions of the secoiridoid nucleus to give the peaks $7,8,30,37$ and 38 with a corresponding molecular ion $[\mathrm{M}-\mathrm{H}]$-of $\mathrm{m} / \mathrm{z}$ 567, 565, 555, 685 and 403 respectively.

\section{Identification of flavonoids}

MS/MS spectral analysis allowed the tentative identification of sixteen flavonoid glycosides peaks 10, 16, 18, 20-23, 26-29, 31-33,
35 and 42, in addition to one aglycone peak 57 (kaempferol), identified flavonoids were tri, di and monoglycosides of kaempferol, quercetin and isorhamnetin flavonoids based on their masses and UV-spectral data analysis. Structure identification was confirmed by MS/MS indicating the fragmentation pathway of each compound, quercetin rutinoside (20), kaempferol rutinoside (27), isorhamnetin hexosyl rhamnoside (29) and kaempferol hexoside (35) were identified in both JSA and JSG with a corresponding molecular ion [M-H] of $\mathrm{m} / \mathrm{z}$ 609, 593, 623 and 447, respectively with aglycone daughter ions 285, 301 and 315 for kaempferol, quercetin and isorhamnetin in the same order. Other kaempferol derivatives were identified peaks 10,21,22, 2342 with a corresponding molecular ion $[\mathrm{M}-\mathrm{H}]$-of $\mathrm{m} / \mathrm{z} 755,739,771,609$ and 593 , quercetin glycosides were identified in peaks $16,18,26,28,31$ and 33 with a corresponding molecular ion [M-H] of $\mathrm{m} / \mathrm{z} 755,625,609,463,579$, 433 respectively, peaks 20,23 and 26 have the same molecular ion peaks $[\mathrm{M}-\mathrm{H}]$-of $\mathrm{m} / \mathrm{z} 609$ and differentiated through MS/MS fragmentation peak 23 give base peaks [M-H] of m/z 447 and 285 with identify the compound to be a kaempferol derivative with dihexoside substitution confirmed by the presence of 447 peak, while MS/MS fragmentation peak 26 give base peaks [M-H]-of $\mathrm{m} / \mathrm{z}$ 447 and 301 with identify the compound to be a quercetin derivative with rutinoside substitution confirmed by the presence of 447 peak which indicates rhamnose substitution direct to the quercetin flavonoid which differs from peak 20 which give base peaks [M-H] of m/z 463 and 301 that show the direct attachment of hexose to the quercetin nucleus.

\section{Identification of lignans}

MS spectral interpretation allowed for the identification of 2 lignans, cycloolivil hexoside and cycloolivil peaks 11 and 53 with a corresponding molecular ion $[\mathrm{M}-\mathrm{H}]-\mathrm{of} \mathrm{m} / \mathrm{z} 537$ and 375 with their characteristic daughter ions of $\mathrm{m} / \mathrm{z} 195,179$.
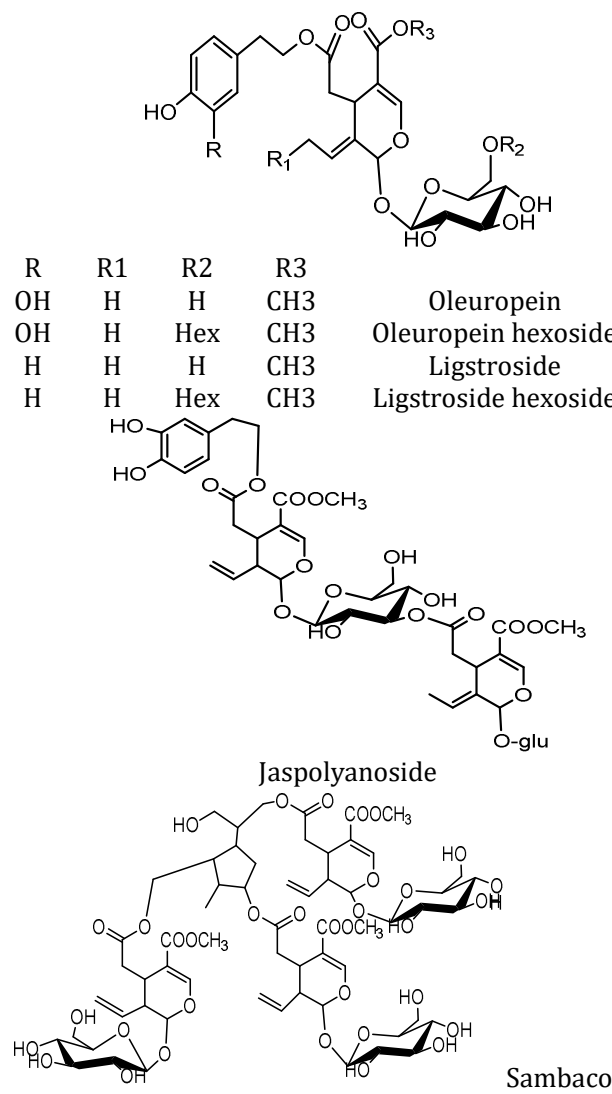

Sambacoside A<smiles>[R]c1ccc(C2c3cc(O)c(OC)cc3CC(O)(CO)C2CO)cc1OC</smiles>

OHcycloolivil

O-HexCycloolivil hexoside

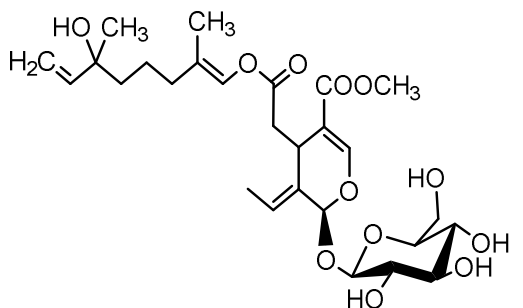

Jaspolinaloside

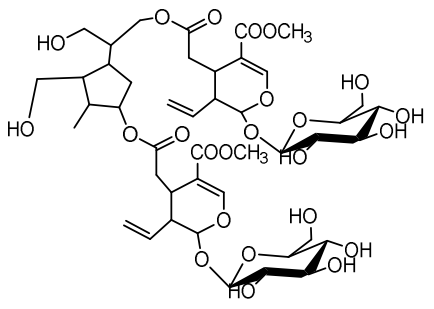

Deacylsambacoside A

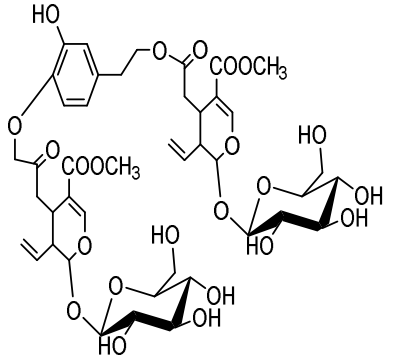

Polyanoside

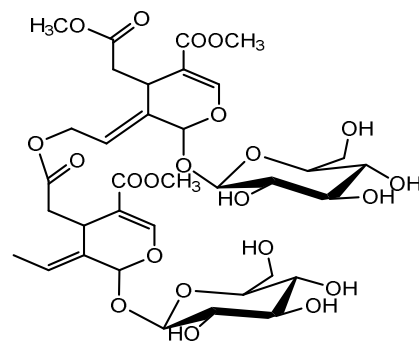

Jaspolyanthoside

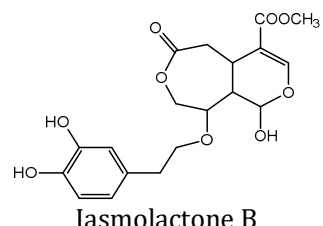

Jasmolactone B

Fig. 5: Chemical structures of some secoiridoid glycosides tentatively identified in the ethanolic extract of JSA and JSG leaves 

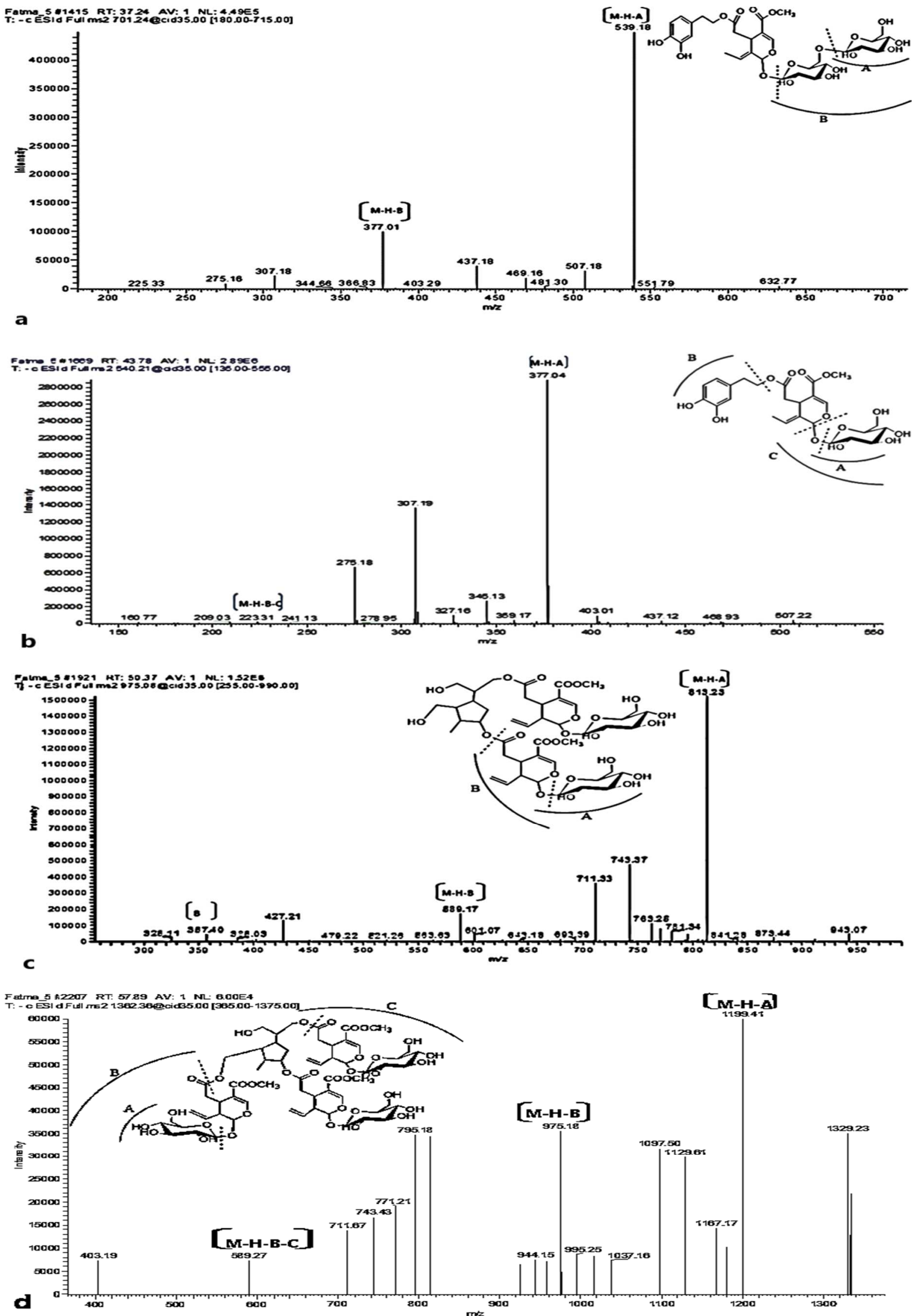

Fig. 6: MS/MS fragmentation pattern of some identified secoiridoid glycosides; a (oleuropein hexoside), b (oleuropein), c (deacyl sambacoside), d (sambacoside A) 


\section{DISCUSSION}

Jasminum sambac L. (Arabian Nights) possessed cytotoxicity against both MCF-7 breast cancer and 5637 bladder cancer, with lower IC 50 of $15.29 \pm 2.16$ and $13.76 \pm 1.11 \mu \mathrm{g} / \mathrm{ml}$ while Jasminum sambac $\mathrm{L}$. (Grand duke of Tuscany) show mild cytotoxicity toward MCF-7 breast cancer and no cytotoxicity toward 5637 bladder cancer, JSA AgNPs give high cytotoxicity with $\mathrm{IC}_{50}$ values $(6.32 \pm 1.01 \mu \mathrm{g} / \mathrm{ml}$ and $5.54 \pm 0.88 \mu \mathrm{g} / \mathrm{ml}$ ) toward both MCF-7 and 5637 cell lines, while JSG AgNPs show lower cytotoxicity toward MCF-7 cell line 17.32 \pm 2.22 $\mu \mathrm{g} / \mathrm{ml}$ and lower cytotoxicity toward 5637 cell line $(27.89 \pm 2.84)$ $\mu \mathrm{g} / \mathrm{ml}$. These results showed that a plant with higher cytotoxic results produces silver nanoparticles with higher characteristics (less particle size and better cytotoxic activities toward the same cell lines). The chemical profile of the JSA cultivar differs from the JSG cultivar. HPLC-PDA-MS/MS of JSA showed the abundance of secoiridoids and secoiridoids glycosides different from JSG like oleoside methyl ester, oleoside dimethyl ester, jasmolactone B, polyanoside, jaspolyanoside, polyanthoside, oleuropein, oleuropein hexoside, ligstroside, and ligstroside hexoside, while common secoiridoids in the two cultivars is sambacoside. Both cultivars showed secoiridoid as a major metabolite, but JSA cultivar possessed a higher abundance of secoiridoid derivatives than JSG.

Flavonoid glycosides were derivatives of kaempferol and quercetin in both cultivars with slight differences among them. From the above fig 3 and table 2, the main components of JSA were; deacyl sambacoside, sambacoside A, quercetin dihexoside, jaspolyanoside, and elonolic acid hexoside, while major compounds in JSG were sambacoside A, sambacolignoside, jasnudifloside $\mathrm{H}$, molihauside $\mathrm{A}$, kaempferol hexoside, kaempferol rutinoside, and oleoside pentoside. These results are in accordance with a previous report on Chinese Jasminum sambac flowers which identified molihauside A, sambacoside A and quercetin hexosides as major constituents[78].

The silver nanoparticles green synthesis with the optimum characters by JSA and their selective cytotoxicity may be attributed to the presence of secoiridoids in this cultivar. Additionally, the chemical profile could be used to distinguish the two cultivars of Egyptian Jasminum sambac (Arabian Nights and Grand Duke of Tuscany)

\section{CONCLUSION}

Jasminum sambac (Arabian Nights) cultivar is an excellent source for the synthesis of green biofriendly silver nanoparticles with selectivity to MCF-7 breast cancer and 5637 bladder cancer cell lines and limited toxicity towards the normal cells, thus offering a high safety margin when used as a cytotoxic agent.

\section{FUNDING}

This research did not receive any specific grant from funding agencies in the public, commercial, or not-for-profit sectors.

\section{AUTHORS CONTRIBUTIONS}

All the authors have contributed equally

\section{CONFLICT OF INTERESTS}

\section{Declared none}

\section{REFERENCES}

1. Bray F, Ferlay J, Soerjomataram I, Siegel RL, Torre LA, Jemal A. Global cancer statistics 2018: GLOBOCAN estimates of incidence and mortality worldwide for 36 cancers in 185 countries. CA: A Cancer J Clin 2018;68:394-424.

2. Trenta P, Calabro F, Cerbone L, Sternberg CN. Chemotherapy for muscle-invasive bladder cancer. Curr Treat Option On 2016;17:6.

3. Kondepati VR, Heise HM, Backhaus J. Recent applications of near-infrared spectroscopy in cancer diagnosis and therapy. Anal Bioanal Chem 2008;390:125.

4. Sanganna B, Chitme HR, Vrunda K, Jamadar MJ. Antiproliferative and antioxidant activity of leaves extracts of Moringa oleifera. Int J Curr Pharm Res 2016;8:54-6.
5. Subbiah RP, Lee H, Veerapandian M, Sadhasivam S, Seo SW, Yun K. Structural and biological evaluation of a multifunctional SWCNT-AgNPs-DNA/PVA bio-nanofilm. Anal Bioanal Chem 2011;400:547-60.

6. Babington R, Matas S, Marco MP, Galve R. Current bioanalytical methods for detection of penicillins. Anal Bioanal Chem 2012;403:1549-66.

7. Sarangi MK, Padhi S. Colon targeted drug delivery system an approach for treating colonic ailments. J Crit Rev 2015;2:9-10.

8. Campbell FW, Compton RG. The use of nanoparticles in electroanalysis: an updated review. Anal Bioanal Chem 2010;396:241-59.

9. Zook JM, Long SE, Cleveland D, Geronimo CLA, MacCuspie RI. Measuring silver nanoparticle dissolution in complex biological and environmental matrices using UV-visible absorbance. Anal Bioanal Chem 2011;401:1993.

10. Menon S, Agarwal H, Kumar SR, Kumar SV. Green synthesis of silver nanoparticles using medicinal plant acalypha indica leaf extracts and its application as an antioxidant and antimicrobial agent against foodborne pathogens. Int J Appl Pharma 2017;9:42-50.

11. Chen X, Schluesener HJ. Nanosilver: a nanoproduct in medical application. Toxicol Lett 2008;176:1-12.

12. Antony E, Sathiavelu M, Arunachalam S. Synthesis of silver nanoparticles from the medicinal plant Bauhinia acuminata and Biophytum sensitivum-a comparative study of its biological activities with plant extract. Int J Appl Pharm 2017;9:22-9.

13. Murugesan S, Bhuvaneswari S, Sivamurugan V. Green synthesis, characterization of silver nanoparticles of a marine red alga Spyridia fusiformis and their antibacterial activity. Int J Pharm Pharm Sci 2017;9:192-7.

14. Sukirtha R, Priyanka KM, Antony JJ, Kamalakkannan S, Thangam R, Gunasekaran P, et al. Cytotoxic effect of green synthesized silver nanoparticles using Melia azedarach against in vitro HeLa cell lines and lymphoma mice model. Proc Biochem 2012;47:273-9.

15. Täckholm V. Ancient Egypt, landscape, flora and agriculture. The Nile, biology of an ancient river: Springer; 1976. p. 51-68.

16. Ito Y, Sugimoto A, Kakuda T, Kubota K. Identification of potent odorants in Chinese jasmine green tea scented with flowers of Jasminum sambac. J Agric Food Chem 2002;50:4878-84.

17. Khan M, Rizwani GH, Zahid H. Standardization of dried flowers of Moringa oleifera (Lamk.) and Jasminum sambac (L.) Ait according to who guidelines. Int J Pharm Pharm Sci 2015;7:19-22.

18. Rambabu B, Patnaik R. Anti diabetic and anti ulcer activity of ethanolic flower extract of Jasminum sambac in rats. Asian J Res Chem 2014;7:580.

19. Sengar N, Joshi A, Prasad SK, Hemalatha S. Anti-inflammatory, analgesic and anti-pyretic activities of standardized root extract of Jasminum sambac. J Ethnopharmacol 2015;160:140-8.

20. Kunhachan $P$, Banchonglikitkul C, Kajsongkram T, Khayungarnnawee A, Leelamanit W. Chemical composition, toxicity, and vasodilatation effect of the flowers extract of Jasminum sambac (L.) Ait."G. Duke of Tuscany". J Evid Based Complement Altern Med 2012. p. 9-18. http://dx.doi.org/10.1155/2012/471312

21. Moloudi MR, Moqbel H, Dastan D, Hassanzadeh K, Nouri B, Izadpanah E. Effect of hydro-alcoholic extract of jasminum sambac on morphine withdrawal symptoms in rats. Sci J Kurdistan Univ Med Sci 2018;23:1-7.

22. Rahman MA, Hasan MS, Hossain MA, Biswas N. Analgesic and cytotoxic activities of Jasminum sambac (L.) aiton. Pharmacologyonline 2011;1:124-31.

23. Houghton P, Fang R, Techatanawat I, Steventon G, Hylands PJ, Lee C. The sulphorhodamine (SRB) assay and other approaches to testing plant extracts and derived compounds for activities related to reputed anticancer activity. Methods 2007;42:377-87.

24. Kalaiselvi M, Narmadha R, Ragavendran P, Ravikumar G, Gomathi D, Sophia D, et al. In vivo and in vitro antitumor activity of Jasminum sambac (Linn) Ait Oleaceae flower against Dalton's ascites lymphoma induced swiss albino mice. Int J Pharm Pharm Sci 2011;4:145-7. 
25. Rivera S, Vilaro F, Canela R. Determination of carotenoids by liquid chromatography/mass spectrometry: effect of several dopants. Anal Bioanal Chem 2011;400:1339-46.

26. Russo M, Fanali C, Tripodo G, Dugo P, Muleo R, Dugo L, et al. Analysis of phenolic compounds in different parts of pomegranate (Punica granatum) fruit by HPLC-PDA-ESI/MS and evaluation of their antioxidant activity: application to different Italian varieties. Anal Bioanal Chem 2018;410:3507-20.

27. Madhavi S, Rani AP. Bioanalytical method development and validation for the determination of sofosbuvir from human plasma. Int J Pharm Pharm Sci 2017;9:35-41.

28. Repetto G, Del Peso A, Zurita JL. Neutral red uptake assay for the estimation of cell viability/cytotoxicity. Nat Protoc 2008;3:1125.

29. Goodin DS, Frohman E, Garmany G, Halper J, Likosky W, Lublin F. Disease modifying therapies in multiple sclerosis. Neurology 2002;58:169-78.

30. Gupta A, Singhal P, Shrivastav PS, Sanyal M. Application of a validated ultra performance liquid chromatography-tandem mass spectrometry method for the quantification of darunavir in human plasma for a bioequivalence study in Indian subjects. J Chromatogr B 2011;879:2443-53.

31. Sobeh M, Mahmoud MF, Abdelfattah MA, El-Beshbishy HA, ElShazly AM, Wink M. Albizia harveyi: phytochemical profiling, antioxidant, antidiabetic and hepatoprotective activities of the bark extract. Med Chem Res 2017;26:3091-105.

32. Noginov M, Zhu G, Bahoura M, Adegoke J, Small C, Ritzo B, et al. The effect of gain and absorption on surface plasmons in metal nanoparticles. Appl Phys B 2007;86:455-60.

33. Ar VN, S0anchez Mendieta V, Camacho Lopez MA, Gomez Espinosa rM, Arenas Alatorre JA. Solventless synthesis and optical properties of $\mathrm{Au}$ and $\mathrm{Ag}$ nanoparticles using Camellia sinensis extract. Mater Lett 2008;62:3103-5.

34. Shankar SS, Ahmad A, Pasricha R, Sastry M. Bioreduction of chloroaurate ions by geranium leaves and its endophytic fungus yields gold nanoparticles of different shapes. J Mater Chem 2003;13:1822-6.

35. Wang H, Cui F, Zhao G. Phenols from buds of Jasminum officinale. Chin J Exp Trad Med Form 2012;14:39-41.

36. Sanz M, de Simon BF, Cadahia E, Esteruelas E, Munoz AM, Hernandez T, et al. LC-DAD/ESI-MS/MS study of phenolic compounds in ash (Fraxinus excelsior L. and F. americana L.) heartwood. Effect of toasting intensity at cooperage. J Mass Spectrom 2012;47:905-18.

37. Rajesh KD, Vasantha S, Panneerselvam A, Rajesh NV, Jeyathilakan N. Phytochemical analysis in vitro antioxidant potential and gas chromatography mass spectrometry studies of dicranopteris linearis. Asian J Pharm Clin Res 2016;9:1-6.

38. Lommen A, Godejohann M, Venema D, Hollman P, Spraul M. Application of directly coupled HPLC- NMR- MS to the identification and confirmation of quercetin glycosides and phloretin glycosides in apple peel. Anal Chem 2000;72:1793-7.

39. Tanahashi T, Nagakura N, Kuwajima H, Takaishi K, Inoue K, Inouye $\mathrm{H}$. Secoiridoid glucosides from Jasminum mesnyi. Phytochemistry 1989;28:1413-5.

40. Ngo QMT, Lee HS, Nguyen VT, Kim JA, Woo MH, Min BS. Chemical constituents from the fruits of Ligustrum japonicum and their inhibitory effects on T cell activation. Phytochemistry 2017;141:147-55

41. Castro J, Krishna MB, Choiniere JR, Marcus RK. Analysis of caffeic acid derivatives in echinacea extracts by liquid chromatography particle beam mass spectrometry (LC$\mathrm{PB} / \mathrm{MS}$ ) employing electron impact and glow discharge ionization sources. Anal Bioanal Chem 2010;397:1259-71.

42. Abdelmohsen M, Nafiz N, Seif el Nasr M. Microwave-assisted extraction of bio-active compounds (phenolics and alkamides) from Echinacea purpurea. Int J Pharma Pharma Sci 2014;6:265-8

43. Zhao G, Xia J, Dong J. Glycosides from flowers of Jasminum officinale L. var. grandiflorum. Yao xue xue bao. Acta Pharm Sin 2007;42:1066-9.

44. Tomassini L, Ventrone A, Frezza C, Serafini I, Bianco A, Cometa MF. Lignans and secoiridoid glycosides from the stem barks of Jasminum tortuosum. Nat Prod Res 2018;32:1853-7.
45. Tanahashi T, Sakai T, Takenaka Y, Nagakura N, Chen CC. Structure elucidation of two secoiridoid glucosides from Jasminum officinale L. var. grandiflorum (L.) Kobuski. Chem Pharm Bull 1999;47:1582-6.

46. Taveira M, Ferreres F, Gil-Izquierdo A, Oliveira L, Valentão $P$, Andrade PB. Fast determination of bioactive compounds from Lycopersicon esculentum mill. leaves. Food Chem 2012;135:748-55.

47. Mattila P, Hellström J. Phenolic acids in potatoes, vegetables, and some of their products. J Food Compos Anal 2007;20:15260.

48. US MR, Zin T, Abdurazak M, Ado Ahmad B. Chemistry and pharmacology of syringin, a novel bioglycoside: a review. Asian J Pharm Clin Res 2015;8:20-5.

49. Lai XJ, Zhang L, Li JS, Liu HQ, Liu XH, Di LQ, et al. Comparative pharmacokinetic and bioavailability studies of three salvianolic acids after the administration of Salviae miltiorrhizae alone or with synthetical borneol in rats. Fitoterapia 2011;82:883-8.

50. Zhang Z, Bian B, Yang J, Tian X. Studies on chemical constitutents in roots of Jasminum sambac. Zhongguo Zhong yao za zhi $=$ Zhongguo zhongyao zazhi $=$ China. $\mathrm{J}$ Chin Materia Med 2004;29:237-9.

51. Llorent Martinez EJ, Gouveia S, Castilho PC. Analysis of phenolic compounds in leaves from endemic trees from Madeira Island. A contribution to the chemotaxonomy of Laurisilva forest species. Ind Crops Prod 2015;64:135-51.

52. Akhov L, Barl B. Isolation of quercetin glycosides from leaves of sea buckthorn (Hippophae rhamnoides ssp. mongolica). XXVI International Horticultural Congress: Berry Crop Breeding, Production and Utilization for a New Century; 2002. p. 389-95.

53. Shen YC, Chen CH. Novel secoiridoid lactones from Jasminum multiflorum. J Nat Prod 1989;52:1060-70.

54. Cao Y, Chu Q, Fang Y, Ye J. Analysis of flavonoids in Ginkgo biloba L. and its phytopharmaceuticals by capillary electrophoresis with electrochemical detection. Anal Bioanal Chem 2002;374:294-9.

55. Elshamy AI, El Gendy A, Farrag A, Nassar MI. Antidiabetic and antioxidant activities of phenolic extracts of Conyza dioscoridis L. shoots. Int J Pharm Pharm Sci 2015;7:65-72.

56. Yang JH, Kondratyuk TP, Marler LE, Qiu X, Choi Y, Cao H, et al. Isolation and evaluation of kaempferol glycosides from the fern neocheiropteris palmatopedata. Phytochemistry 2010;71:6417.

57. Bhushan B, Sardana S, Bansal G. Acute and sub-acute toxicity study of clerodendrum inerme, jasminum mesnyi hance and callistemon citrinus. J Acute Dis 2014;3:324-7.

58. Simirgiotis MJ, Silva M, Becerra J, Schmeda Hirschmann G. Direct characterisation of phenolic antioxidants in infusions from four mapuche medicinal plants by liquid chromatography with diode array detection (HPLC-DAD) and electrospray ionisation tandem mass spectrometry (HPLC-ESI-MS). Food Chem 2012;131:318-27.

59. Takenaka Y, Takahashi T, Nagakura N. Eight minor secoiridoid glucosides with a linear monoterpene unit from Jasminum polyanthum. Chem Pharm Bull 1998;46:1776-80.

60. Shen YC, Lin SL, Chein CC. Three secoiridoid glucosides from Jasminum lanceolarium. Phytochemistry 1997;44:891-5.

61. Karima S, Nadine C, Fadila B, Maurice J. Characterization and distribution of flavonoids from flowers in different horticultural types of begonia. Pharmacogn J 2017;9:850-5.

62. Eyles A, Jones W, Riedl K, Cipollini D, Schwartz S, Chan K, et al. Comparative phloem chemistry of manchurian (Fraxinus mandshurica) and two North American ash species (Fraxinus americana and Fraxinus pennsylvanica). J Chem Ecol 2007;33:1430-48.

63. Zhao G, Yin Z, Dong J. A new secoiridoid from the flowers of Jasminum officinale L. var. grandiflorum. Yao xue xue bao. Acta Pharm Sin 2008;43:513-7.

64. Amiot MJ, Fleuriet A, Macheix JJ. Accumulation of oleuropein derivatives during olive maturation. Phytochemistry 1989;28:67-9.

65. Chen HY, Shen YC, Chen CH. Jasmultiside, a new secoiridoid glucoside from Jasminum multiflorum. J Nat Prod 1991;54:1087-91. 
66. HAO T, Zhang SF, Zhao GQ. Study on quality standard of total iridoid glycosides from Jasminum officinale L. var grandiflorum [J]. Lishizhen Med Mater Med Res 2013;1:28-31.

67. El-Sayed NH, Wojcińska M, Drost Karbowska K, Matławska I, Williams J, Mabry TJ. Kaempferol triosides from silphium perfoliatum. Phytochemistry 2002;60:835-8.

68. Zhang YJ, Liu YQ, Pu XY, Yang CR. Iridoidal glycosides from Jasminum sambac. Phytochemistry 1995;38:899-903.

69. Tanahashi T, Takenaka Y, Nagakura N. Three secoiridoid glucosides esterified with a linear monoterpene unit and a dimeric secoiridoid glucoside from Jasminum polyanthum. J Nat Prod 1997;60:514-8.

70. Takenaka Y, Tanahashi T, Taguchi $H$, Nagakura N, Nishi T. Nine new secoiridoid glucosides from jasminum nudiflorum. Chem Pharm Bull 2002;50:384-9.

71. Yue Z, Qin H, Li Y, Sun Y, Wang Z, Yang T, et al. Chemical constituents of the root of Jasminum giraldii. Molecules 2013;18:4766-75

72. Tanahashi $\mathrm{T}$, Nagakura $\mathrm{N}$, Inoue $\mathrm{K}$, Inouye $\mathrm{H}$, Shingu $\mathrm{T}$. Sambacolignoside, a new lignan-secoiridoid glucoside from Jasminum sambac. Chem Pharm Bull 1987;35:5032-5.

73. Guo ZY, Li P, Huang W, Wang JJ, Liu YJ, Liu B, et al. Antioxidant and anti-inflammatory caffeoyl phenylpropanoid and secoiridoid glycosides from Jasminum nervosum stems, a Chinese folk medicine. Phytochemistry 2014;106:124-33.

74. Tanahashi T, Nagakura N, Inoue K, Inouye H, Sambacosides AEF. Novel tetrameric iridoid glucosides from Jasminum sambac. Tetrahedron Lett 1988;29:1793-6.

75. Häkkinen SH, Kärenlampi SO, Heinonen IM, Mykkänen HM, Törrönen AR. Content of the flavonols quercetin, myricetin, and kaempferol in 25 edible berries. J Agric Food Chem 1999;47:2274-9.

76. Perez Bonilla M, Salido S, Van Beek TA, de Waard P, Linares Palomino PJ, Sanchez A, et al. Isolation of antioxidative secoiridoids from olive wood (Olea europaea L.) guided by online HPLC-DAD-radical scavenging detection. Food Chem 2011;124:36-41.

77. Obied HK, Prenzler PD, Ryan D, Servili M, Taticchi A, Esposto S, et al. Biosynthesis and biotransformations of phenolconjugated oleosidic secoiridoids from olea europaea L. Nat Prod Rep 2008;25:1167-79.

78. Yin Y, Ying X, Luan $\mathrm{H}$, Zhao Z, Lou J, Wang D, et al. UPLCDAD/Q-TOF-MS based ingredients identification and vasorelaxant effect of ethanol extract of jasmine flower. J Evid Based Complement Altern Med 2014. http://dx.doi.org/ $10.1155 / 2014 / 707908$. 